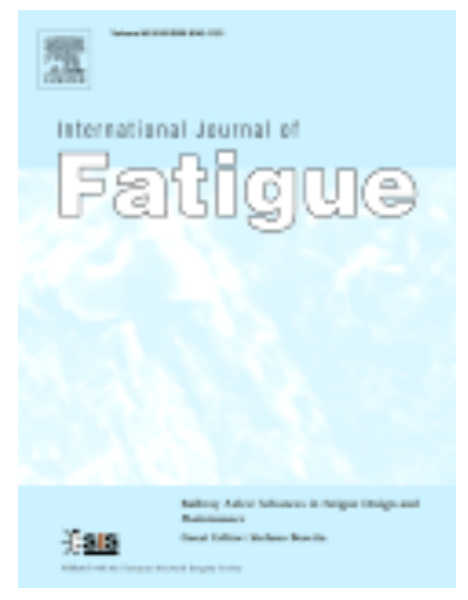

Probabilistic fatigue assessment for railway axles and derivation of a simple format for damage calculations

by S. Beretta, D. Regazzi

Int. J. Fatigue, 2016, Vol. 86, pp. 13-23

doi:10.1016/j.ijfatigue.2015.08.010 


\title{
Probabilistic fatigue assessment for railway axles and derivation of a simple format for damage calculations
}

\author{
S. Beretta*, D. Regazzi \\ Politecnico di Milano, Dipartimento di Meccanica, Via La Masa 1, 20156 Milano (IT)
}

\begin{abstract}
This paper describes a procedure for the determination of railway axle risk of fatigue failure under service loading for a simple fatigue assessment compliant to modern structural recommendations.

After an initial review of reliability assessment under fatigue, a fully probabilistic approach is outlined, whose input data for the fatigue damage obtained with the EURAXLES project are briefly summarised. Then, a series of Montecarlo simulations was carried out in order to determine the maximum allowable stress for a given axle made of EA4T and EA1N under service conditions identified by different load spectra from the literature.

Results have been obtained in terms of a safety factor for damage calculations that allows designers to adopt a simple semi-probabilistic approach for designing axles for a target reliability against fatigue. The application of this procedure to a railway axle then shows how safety factors should be have to be further increased for taking into the prospective presence of impact damages.
\end{abstract}

Keywords: railway axles, fatigue, failure probability, safety factor

\section{NOMENCLATURE}

$a_{0}$ - initial crack size

$C$ - parameter of the $\mathrm{S}-\mathrm{N}$ diagram power equation

$D$ - calculated fatigue damage

$D_{\text {crit }}$ - critical value of the calculated damage

$C V_{X}$ - coefficient of variation for the $\mathrm{X}$ variable

$C V_{S}$ - coefficient of variation for the classes of the service spectrum

$k$ - slope of the S-N diagram for $S>S_{D}$

\footnotetext{
* Corresponding author

Email address: stefano.beretta@polimi.it (S. Beretta)
} 
$k^{\prime}$ - slope of the S-N diagram for damage calculation for $S<S_{D}$

$j_{D}$ - safety factor for fatigue damage adopted by FKM Guideline

$N_{D}$ - number of cycle for the knee of the S-N diagram

$P_{f}$ - failure probability

$\hat{P}_{f}$ - target failure probability

$S_{D}$ - stress amplitude for the knee of the S-N diagram (fatigue strength)

$S_{D, c h a r}$ - characteristic value of fatigue strength for assessment

$S_{i}$ - stress amplitude for the i-th class of a service spectrum

$S_{L}$ - single load condition for the assessment under constant amplitude

$S_{\max }$ - maximum stress amplitude (or stress amplitude of the highest class) of a service spectrum

$S_{\text {max,perm }}$ - maximum permissible stress amplitude (or stress amplitude of the highest class) for obtaining a failure probability $P_{f} \leq \hat{P}_{f}$

UTS - ultimate tensile strength

$\beta$ - safety margin for failure probability calculations

$\Delta K_{\max , o}$ - initial SIF range calculated at the maximum stress of service spectrum for $\overline{a_{0}}$

$\eta$ - safety factor for fatigue strength adopted by EN13103/104

$\eta_{D}$ - safety factor for axle damage calculations adopting FKM format

$\gamma_{M f}$ - safety factor for fatigue damage adopted by Eurocode 3

$\lambda$ - failure rate

$\mu_{X}$ - mean value for the $\mathrm{X}$ variable

$\bar{X}$ - median for the $\mathrm{X}$ variable

$\Phi$ - normal standard cumulative distribution function

$\sigma_{X}$ - standard deviation for the $\mathrm{X}$ variable 


\section{INTRODUCTION}

Railway axles are primary safety components designed for an infinite life and real their service life can last 30 years. The current design rules, now incorporated in EN13103/13104 [1, 2], dates back to ERRI B136 report \#11 [3], which stated the principles for designing the axle loads, the admissible fatigue limit stress for EA1N steel and the concepts for axle fatigue experiments. The current EN design rules does not consider any degradation of the axle surface due to the long service (accidental damages, impacts, corrosion), therefore it is needed that maintenance and inspections, whose periodicity has to be determined on damage tolerance principles (see $[4,5]$ ), should ensure the structural reliability of the axle. The consequence of both actions (design and inspections) is that axle reliability records are very good (see recent documents $[6,7]$ ) and they are already compliant to modern structural reliability requisites (see discussion in Sec. 3).

If on one side most of the recent literature about fatigue of axles has been devoted to damage tolerance concepts and tools, on the other hand only a few papers have dealt with fatigue design discussing that axles with the same safety against fatigue may have very different residual lifetime $[8,9]$ and that an axle designed for fatigue safe life [10] can have a very short residual propagation lifetime [11]. These are the reasons why any actions for improving the reliability and design of axles would need to propose modern methods for the fatigue assessment based on probabilistic concepts.

This was the address of the research project EURAXLES, aimed at minimizing the risk of fatigue failure of railway axles. In particular, the results consist in new fatigue data for consolidating current design limits and new tools for modern design (FE analysis, fatigue assessment under service loads, damage calculations) and future design exploitations. In this paper, we start from a summary of the results about fatigue properties of full-scale axles obtained in EURAXLES for proposing a robust approach for designing railway axles with 
a target reliability.

\subsection{Scope - Standards for fatigue assessment}

The current standards EN13103/13104 [1,2] are based onto simple calculations by Releaux [12] for identifying reference maximum axle loads for a given train wagon. Recent analyses carried out within EURAXLES have shown that the calculated local axle stresses correspond to a conservative estimation of the upper levels of the service stress spectrum [13]. A local fatigue assessment is then carried out, under the assumption of constant amplitude loading under those conservative axle loads, considering reference fatigue strengths divided by a minimum safety factor $\eta=1.2$ for EA1N steel and $\eta=1.33$ for EA4T steel.

The limitations with EN Standards methods are: i) it is not clear what are the levels of failure probability associated with these simple indications, firstly because the axle fatigue strength to be considered is not explicitly related to a prospective strength distribution; ii) the design procedure does not consider the possibility of an analysis based on fatigue damage, while it is considered in other standards. In the following the prescriptions by EUROCODE 3 [14] and FKM Guidelines [15] are illustrated.

\section{Eurocode 3}

According to EUROCODE 3, the fatigue assessment of a given structural details can be done considering the S-N characteristic curves for the different details. In particular, the design curves correspond to a $P_{f}=5 \%$ failure probability and they have the typical bi-linear shape suggested by Haibach, with slopes $k=3$ and $k^{\prime}=2 k-1=5$ and a knee at $N_{D}=5 \cdot 10^{6}$ cycles.

The assessment (both for constant amplitude and variable amplitude loading) is done considering a design curve which corresponds to the characteristic curve divided by an appropriate safety factor $\gamma_{M f}$, reported in Tab. 1. Considering that a railway axle is a safety critical component, according to EUROCODE 3 the safety factor should be in the range $1.15-1.35$. 


\section{FKM Guideline}

The FKM Guideline appears to follow the same approach (even if it is more detailed). In particular, it prescribes a characteristic curve, in terms of stress amplitude, corresponding to a $P_{f}=2.5 \%$ failure probability. The design curve is once again determined by applying a safety factor (named $j_{D}$, reported in Tab. 2) to the characteristic fatigue strength.

The critical damage sum according to the FKM Guideline should be carried out according to Miner Konzequent -MK method and its critical value depends on the material: for steel components the values to be considered for damage calculations are $k=5$ and $D_{\text {crit }}=0.3$. A more simple alternative to the $M K$ method is to consider the Haibach's bilinear approximation with a slope $2 k-1$ for stress cycles with $S_{a}<S_{D}$ (the calculation with Haibach's hypothesis is a conservative first approximation of the MK calculation).

The FKM approach appears to be more conservative than EUROCODE 3 and it considers that, under variable amplitude loading, the typical damage sum is lower than $1[16,17]$. On the other hand, the problems of the FKM approach, in common with EUROCODE 3, are:

- the value of the safety factor does not appear to be related to the scatter of the load/stress, while it should depend on the dispersion of the stress;

- there is not an explicit definition of which percentile of the stress has to be considered and the target reliability is unknown.

\subsection{Problem statement}

The aim of this paper is to overcome the limitations of the current standards and to propose a simple solution to the problem depicted in Fig. 2 : how to calculate failure probability for a railway axle under a given local stress spectrum considering both the dispersion of fatigue lives and a prospective uncertainty/scatter of the local stress spectrum. The idea behind this approach is that load spectra of a given train can be measured or simulated: the designer needs to know how to deal with it for a fatigue assessment and how to 
determine maximum design stresses able to grant a target failure probability $\hat{P}_{f}$.

The inputs for the probabilistic model, resulting from literature data and the database of fatigue tests obtained in EURAXLES, will be shown in Sec. 2. The probabilistic model and its results will be discussed in Sec. 3. Eventually, an equivalent set of partial safety factors will be proposed in Sec. 4. The impact of the extra requirement of maintenance and inspection on maximum design stresses is discussed in Sec. 5 .

\section{Probabilistic fatigue assessment}

\subsection{Failure probability under constant amplitude stress}

The most simple case for a probabilistic fatigue assessment is to consider an axle with a local fatigue strength described by a gaussian distribution with parameters $\left(\mu_{\log S_{D}}, \sigma_{\log S_{D}}\right)$ that is subjected to a constant stress $S_{L}$ for an infinite number of cycles (or $n>N_{D}$ ) as shown in Fig. 3. The failure probability can then be simply calculated as [18]:

$$
P_{f}=\Phi(-\beta)
$$

where:

$$
\beta=\frac{\mu_{\log S_{D}}-\log S_{L}}{\sigma_{\log S_{D}}}
$$

\subsection{Fatigue damage under VA loading}

A probabilistic assessment of fatigue under variable amplitude can be obtained by referring to the concepts of stress spectrum and damage. Firstly we need to express the $\mathrm{S}-\mathrm{N}$ diagram as:

$$
N=\frac{C}{S^{k}}
$$

where $C=N_{D} \cdot S_{D}^{k}$. It is easy to recognize that, because of the variability of fatigue life, $C$ is a random variable (see Fig. 4) which belongs to a lognormal 
distribution with parameters:

$$
\left\{\begin{array}{l}
\mu_{\log C}=\log \left(N_{D} \cdot S_{D}^{k}\right) \\
\sigma_{\log C}=\sigma_{\log N}
\end{array}\right.
$$

where $\sigma_{\log N}$ is the dispersion of fatigue lives, that could be estimated with an appropriate interpolation of fatigue data [19]. The damage of a stress spectrum divided into $l$ classes can be expressed as:

$$
D=\frac{1}{C} \cdot \sum_{i=1}^{l} n_{i} \cdot S_{i}^{k}
$$

that can be rewritten as:

$$
\log D=-\log C+\log \left(\sum_{i=1}^{l} n_{i} \cdot S_{i}^{k}\right)
$$

This equation shows that $\log D$ is a gaussian random variable with the same scatter as the fatigue life $\left(\sigma_{\log D}=\sigma_{\log N}\right)$. The calculation of the failure probability can be simply done as:

$$
P_{f}=\operatorname{Prob}\left[D>D_{\text {crit }}\right]=\Phi(-\beta)
$$

with:

$$
\beta=\frac{D_{c r i t}-\mu_{\log D}}{\sigma_{\log D}}=\frac{D_{c r i t}-\mu_{\log D}}{\sigma_{\log N}}
$$

where $D_{\text {crit }}$ represents the Miner index at failure.

This probabilistic formulation for damage calculations (known as lognormal format [20] ) has the advantage of being easily applicable in a Montecarlo simulation since the realizations of the damage can be obtained by simply calculating $D$ onto different realizations of the S-N diagram. Moreover, this approach is able to simply include the relative Miner rule $[16,17]$, the fact that usually $D_{\text {crit }} \neq 1$ and that it depends on the material type (as acknowledged by $F K M[15]$ ). 


\subsubsection{Bignonnet Method}

An alternative to the lognormal format is the approach firstly proposed by Bignonnet $[21,22]$ and adopted by SNCF for deliverable D2.2 [13].

The first step of the method by SNCF consists in calculating an equivalent constant amplitude stress $\left(N_{e q}, S_{e q}\right)$ which has the same damage as the analysed spectrum. In particular, by taking $N_{e q}=N_{D}$, the equivalent stress for a given spectrum with damage $D$ can be calculated as:

$$
S_{e q}=\left(\frac{D}{D_{\text {crit }}}\right)^{(1 / k)} \cdot S_{D}
$$

The second step of the SNCF method consists in generating various load spectra to take into account the various axle usages. Equivalent loads for these different spectra are calculated and finally the distribution of equivalent load is then obtained

The failure probability, being $S_{e q}$ a distribution, can then be calculated with different methods (for example: algebra of gaussian variables, integral transform) [23].

\section{Input data for a probabilistic fatigue assessment of railway axles}

\subsection{Definition of a reference $S-N$ diagram for $A 4 T$}

Since in EURAXLES the fatigue tests have been concentrated onto a consolidation of the fatigue limit [24], it has been impossible to obtain a full-scale S-N diagram. Nevertheless, the prospective S-N diagram for a full-scale component and its potential comparison with small scale data is schematically shown in Fig. 6(a) (adapted from [25]), where it can be seen that surface roughness and volumetric effect can lead to a reduction of fatigue strength for a full-scale component together with a change in the slope for the S-N diagram and a shift in the position of the knee.

Therefore the slope of the S-N diagram for full-scale axles has been deduced, applying this schematic, from the S-N diagram for small specimens 
[26] and a dataset of fatigue data of full scale axles from EURAXLES and a previous research project $[27,24]$ (the data pertain to three batches with $U T S=700[\mathrm{MPa}])$. In particular: i) the position of the knee $N_{D}$ has been taken as the one of the small scale specimens; ii) the slope $k$ has been estimated from the S-N diagram of small scale specs at $N=10^{4}$ cycles; iii) the fatigue limit of full-scale axles has been estimated through the ML method [28] assuming a log-normal distribution for fatigue strength.

The resulting parameters of the estimated S-N diagram for EA4T are shown in Tab. 3. The fatigue limit here estimated is very close to the result in [24], where the full-scale data were analyzed assuming a gaussian distribution for fatigue strength. The prospective $\mathrm{S}-\mathrm{N}$ diagram for A4T is shown in Fig. 6(b) together with the full-scale test data available. As expected, the $\mathrm{S}-\mathrm{N}$ diagram is slightly conservative respect to data points.

\subsection{Definition of a reference $S$ - $N$ diagram for $A 1 N$}

The same procedure of A4T (estimate of $k$ and $N_{D}$ from small scale specimens) has been used for A1N, considering the distribution of fatigue strength estimated by ML method by merging EISBFW [27] and EURAXLES [24] fullscale data. Since the fatigue limit of small-scale specimens is almost coincident with the fatigue limit of full-scale axles, the slope of the small scale specimens [29] was adopted (without any correction as In Fig. 6.a). Parameters of the estimated S-N diagram for EA1N are reported in Tab. 4.

The resulting prospective S-N diagram for A1N, shown in Fig. 7, is consistent with the available A1N full-scale test data.

\subsection{Miner Index at failure}

A series of variable amplitude fatigue tests have been carried out within EURAXLES by IWM and PoliMi. The tests were carried out onto axial resonant testing machines under constant amplitude stress (derivation of S-N diagram), simple load sequences and random sequences of block loads derived from a stress 
spectrum measured during the EURAXLES project [30]. Details of the tests and results are reported in [31].

The results, in terms of damage index at failure calculated with the $M K$ method and the Haibach's method are shown in Fig. 8. The statistics of the two indexes are reported in Tab. 5.

It is of some importance to remark that the damage indexes are lognormally distributed, as could be predicted by probabilistic damage calculations in Sec. 3.1 , with a scatter compatible with the scatter of the bilinear S-N diagram for $S<S_{D}$ (this is expected since in the applied stress sequences most of the cycles were below the knee of the $\mathrm{S}-\mathrm{N}$ curve). The conclusion that can be drawn is that, for fatigue damage calculations in railway axles made of $\mathrm{A} 4 \mathrm{~T}$, the critical fatigue damage can be taken as $D_{\text {crit }}=0.5$. This value is higher than the average value for steels proposed in [32] (which looks to support the FKM Guideline) and it corresponds to the value suggested by Grubisic and Fisher [10]. Moreover, the results confirm that Haibach's method is a simple and conservative approximation for damage calculations. Therefore it has been considered for a simple application of correct fatigue analysis for railway axles. Since no variable amplitude test has been carried out onto EA1N, the same value of the critical fatigue damage has been considered for the two steels.

\subsection{Target reliability and failure rate for railway axles}

As for the admissible failure probability of a railway axle, EN1990 [33] defines a target failure probability for a construction during the entire life:

$$
P_{f, E N 1990}=7 \cdot 10^{-5}
$$

If we express the reliability as [23]:

$$
R(t)=\exp (-\lambda \cdot t)
$$


where $\lambda$ is the failure rate, we can then calculate (for 30 years corresponding to $\left.10^{7} \mathrm{~km}\right)$ :

$$
\lambda_{E N 1990}=2.33 \cdot 10^{-6} \quad[\text { failures } / \text { year }]
$$

On a fleet of a million axles, this would correspond to approx. 2 axle failures per year. This figure is very close to the present situation in Europe: ERA reports an average 40 axle failures per year in 2010-2011-2012 in the 27 countries of $\mathrm{EU}[6,7]: 10 \%$ of these failures are due to mechanical causes [34]. In order to improve this figure, we might reduce the target failure probability of one order of magnitude by setting:

$$
\lambda_{i m p}=2.33 \cdot 10^{-7} \quad \rightarrow \quad P_{f, i m p}=7 \cdot 10^{-6}
$$

It is interesting to observe that $\lambda_{i m p}$ corresponds to the target failure rate defined by RSSB [35] for improving the reliability of axles respect to the present situation.

\section{Probabilistic fatigue damage calculations for railway axles}

\subsection{Format for the calculations}

The reason for a probabilistic assessment is the verification of the robustness of a design against the variability of strength (in our case the fatigue properties) and the uncertainty of loads (in this case the stress specrum). Considering the fatigue properties obtained in EURAXLES (recapitulated in the previous section), the procedure for calculating the failure probability for a railway axle under a given service stress spectrum can be so summarized:

- the fatigue damage can be calculated with the Haibach's hypothesis onto the average S-N diagram for A4T and A1N defined in Sec. 3.3;

- the variability of fatigue life can be described as a bi-linear diagram (with slopes slopes $k$ and $2 k-1$ ) with a constant scatter that corresponds to the scatter of $\sigma_{\log S_{D}}$; 
- the critical Miner Index is $D_{\text {crit }}=0.5$;

- the prospective axle life is $10^{7}$ kilometers.

A series of Montecarlo simulations have been run in order to determine the dependence of failure probability on the maximum stress of the service spectrum considering high speed axles (made of EA4T) and freight axles (made of A1N).

Since the scatter of the fatigue strength for $\mathrm{A} 4 \mathrm{~T}$ and $\mathrm{A} 1 \mathrm{~N}$ is not the same and, in the case of A4T, it is very low (due to analysis of data sets from axle steels with similar properties), it is difficult to make a choice about the correct value of $\sigma_{\log S_{D}}$. Therefore the calculations have been carried out with the different values of the scatter reported in Tab. 6 together with the prospective coefficient of variation (ratio of standard deviation to mean value).

The other essential point for a probabilistic analysis is to take into account the variability (or better the uncertainty) about the loading conditions. According to BS7910 [36], the CV for the applied primary loads in a structure falls in the range $0-0.3$. We can imagine that the stress spectrum has been already obtained as the combination of different stress spectra obtained by measurements $[37,13]$ or dynamic simulations [38] for different load cases (full loaded vehicle or empty vehicle, different routes), then a coefficient of variation $C V_{S}$ has been taken as a measure of the uncertainty in the evaluation of the design stress spectrum. Since we usually refer to stress spectra in terms of amplitudes, then the coefficient of variation $C V_{S}$ in the simulations have been taken as: $C V_{S}=0.01,0.05,0.10,0.15$. These discrete values correspond to same interval of BS7910 for the stress ranges.

\subsubsection{Montecarlo simulations}

The Montecarlo simulations have been run considering essentially two random variables:

1. the position of the S-N diagram, described by the gaussian variable variable $\log S_{D}$ whose scatter is reported in Tab. 6; 
2. the stress amplitudes of the different classes of the load spectrum, that are treated as perfectly correlated gaussian variables (all the the classes, in the $i$-th realization of the spectrum, have the same $z_{i}$ gaussian standardized variable) described by a coefficient of variation $C V_{S}$.

After extracting the two random variables (5 $10^{6}$ extractions) the Miner Index for each combination spectrum/S-N diagram has been calculated (with the Haibach's hypothesis) in order to obtain a sample of $N_{\text {sim }}$ damage realizations to be compared with $\bar{D}_{\text {crit }}$. In particular, according to Eq.(7), the failure probability has been calculated:

$$
P_{f}=\operatorname{Prob}\left[D>D_{c r i t}\right]
$$

after interpolating the sample of $N_{\text {sim }}$ realizations with a lognormal distribution.

\subsection{Stress spectra}

Different stress spectra have been considered for the analyses (they are shown in Fig. 9). In the case of high speed trains, three spectra have been considered: i) the stress spectrum measured on a high speed axle with the EU-FP6 Project WIDEM [39]; ii) the stress spectrum obtained within the EU-FP5 project HYPERWHEEL (spectrum II of [40]); iii) a gaussian stress spectrum with $\mathrm{CV}=0.3$.

For the freight axles the two spectra here considered are: i) the stress spectra measured on the axles of the Kiruna iron ore line [39]; ii) the stress spectrum for a freight wagon with Y25 bogie simulated with the EU-FP7 project SUSTRAIL [41].

\subsection{Results}

The results in terms of failure probability vs. maximum local stress of the spectrum are shown in Fig. 10 for the high speed train (WIDEM spectrum) and the freight axle (SUSTrail spectrum). It can be clearly seen how the failure probability strongly depends on the maximum stress of the spectrum, but 
for a given $S_{\max , s p}$ the uncertainty of the load spectrum controls the failure probability.

A series of trial and errors simulations were carried out for determining for each spectrum the maximum stress that could correspond to a target failure probability. In detail:

$$
S_{\text {max }, \text { perm }}=\max \left(S_{\text {max }}\right): P_{f} \leq\left\{\begin{array}{c}
\hat{P}_{f, E N 1990} \\
\hat{P}_{f, \text { imp }}
\end{array}\right\}
$$

Detailed results for the combinations here considered (5 stress spectra, 2 S$\mathrm{N}$ diagrams, 4 different values for $C V_{S}$ and 4 different values for $\left.\sigma_{\log S_{D}}\right)$ are reported in Appendix.

\section{Discussion on safety factors for axle fatigue calculations}

It is worth revising the design approach by the EN standards in two direction: i) a probabilistic analysis for determining the minimum safety factor to be applied to a conservative constant amplitude fatigue assessment; ii) the definition of a safety factor for a simple fatigue assessment under a design stress spectrum for condensing the results obtained in the previous section.

\subsection{Safety factors and reliability under constant amplitude stress}

Under assumption of constant amplitude loading, it is possible to define a minimum safety factor. If we consider consider a target failure probability $\hat{P}_{f}$, we can then define:

$$
\hat{\beta}=\Phi^{-1}\left(\hat{P}_{f}\right)
$$

Therefore in order to have a failure probability lower than the target, the stress should be as low as:

$$
\log S_{L} \leq \mu_{\log S_{D}}-\hat{\beta} \cdot \sigma_{\log S_{D}}
$$

Considering a minimum characteristic strength $S_{D, \text { char }}$, the partial safety factor to be applied for a safe design (where safe refers to a failure probability lower 
than the target) is:

$$
\eta_{\min }=\frac{S_{D, c h a r}}{10^{\mu_{\log S_{D}}-\hat{\beta} \cdot \sigma_{\log S_{D}}}}
$$

Following the FKM Guideline, which considers the $2.5 \%$ percentile as the characteristic value for strength, we can then calculate the minimum safety factor to be applied in a simple fatigue assessment under constant load. In particular, considering different prospective values for the scatter of fatigue strength we obtain the safety factors reported in Tab. 7 .

Considering that the fatigue strength of the EA1N full-scale axles has $C V \approx$ 0.13 , it can then be considered that the safety factor $\eta=1.2$ of the standards would need to be slightly increased to $\eta=1.27$, provided that the characteristic strength is fixed at the $2.5 \%$ percentile. This value should be then become 1.36 if the failure probability had to reach the target $\hat{P}_{f}=7 \cdot 10^{-6}$.

As for EA4T, the minimum safety factors should be $1.15-1.20$ because of the lower dispersion of fatigue strength. Oppositely, EN13103/13104 [1, 2] prescribe an increase of the safety factor of $111 \%$ for taking into account that EA4T is more sensible to the presence of notches/scratches (potentially due to problems in in axle machining) than EA1N.

\subsection{Safety factors for damage calculations}

The previous probabilistic calculation procedure appears to be a little complicated for a designer, since a Montecarlo simulation is needed. For the sake of a practical use, the results obtained in the Appendix have been processed by calculating, for a given combination of $S_{\text {max,perm }}$ and $\hat{P}_{f}$, the minimum safety factor to be adopted for calculating the same maximum stress with a simple damage calculation with the FKM format (characteristic strength at $2.5 \%$ and $\left.D_{\text {crit }}=0.3\right)$. The results of these calculations are also reported in the tables in Appendix and they are shown in Fig. 12(b) for high speed axles (made of EA4T, conservatively it has been assumed $\left.\sigma_{\log S_{D}}=0.033\right)$ and freight axles (made of EA1N, $\sigma_{\log S_{D}}=0.057$ ). 
It is interesting to see that the minimum safety factor does not depend very much on the stress spectrum shape and the slope of S-N diagram: the results for the two axle steels are very similar (see Appendix), the difference between the two plots of Fig. 12(b) is simply due to the different $\sigma_{\log S_{D}}$ considered. The value of $\eta_{D}$ decreases with $C V_{S}$ and it is close $\eta_{\min }$ for $C V_{S} \rightarrow 0$. It can be also added that the safety factor $j_{D}=1.35$ prescribed by FKM (primary component with regular inspections) appears to be inadequate for a steel like EA1N with $\sigma_{\log S_{D}}=0.057$, while it can be considered for a steel with $\sigma_{\log S_{D}}=0.033$ (such as the EA4T steel) only if the uncertainty in the definition of the load spectrum is lower than 0.075 .

\section{Strength degradation in service and inspections}

The previous results of the probabilistic analysis, obtained in terms of a partial safety factor $\eta_{D}$ that allows designers to adopt a simple semi-probabilistic approach for design of axles with a target reliability, are correct under the assumption of the S-N data shown in Sec. 3. This implies that 'protection and maintenance policy applied to the axle ensures the efficiency of the protection against impacts and corrosion throughout the life of the axle and ensures that the original surface condition of the axle material is maintained' (quote from EN13103-13104 [1, 2]).

The key point in this statement is not the need for maintenance, but rather the periodicity of the inspections that have to be carried out for deciding if an axle has to be maintained (or in extreme conditions withdrawn from service). The inspection periodicity has be determined so that the axle remains safe during its service until the next check. The surface of an axle is subjected to degradation mainly due to impacts (ballast hits, accidental damage) and corrosion-fatigue. Among the two phenomena, corrosion-fatigue is a much slower progress than the propagation of a crack by fatigue $[42,43]$. Therefore it is more conservative to calculate the inspection interval for the fatigue propagation of a prospective surface damage. Such an analysis would need a approach 
considering the following variables: i) the distribution of impacts depth; ii) the distribution of crack growth properties; iii) the uncertainty of a given load spectrum; iv) the probability of detection curve for the inspection method adopted $($ see $[4,5])$.

The calculation of inspection periodicity is beyond the scope of the present research. Alternatively, we considered a simplified analysis about the effect of $S_{\max }$ on propagation life for an axle made of EA4T subjected to the WIDEM stress spectrum. In detail, the life corresponding to a failure probability $P_{f}=7 \cdot 10^{-5}$ has been estimated with a latin hypersquare approach [44] adopting the NAGRO propagation equation [45]. The three main variables for propagation lifetime have been taken as as: i) flaw depth described by a Weibull distribution with $\bar{a}_{o}=0.8[\mathrm{~mm}][46]$; ii) $\Delta K_{t h}$ described by gaussian distribution with an appropriate scatter (data obtained from [47] and from the WOLAXIM project [48]); iii) uncertainty for the WIDEM spectrum described by a gaussian distribution with $C V_{S}=0.01-0.05-0.1$. The results of the simplified calculations, that has been carried out for different values of $S_{\max }$, are shown in Fig. 12.

As it can be seen, the minimum propagation lifetime is controlled, at any $C V_{S}$, by the maximum stress of the stress spectrum. Considering that the typical periodicity for an high speed train is $200,000 \mathrm{~km}$ and that a reasonable assumption for the WIDEM measurements is $0.05<C V_{S}<0.1$ [39], then the maximum stress spectrum should be $137<S_{\max }<147[\mathrm{MPa}]$. These stresses correspond to safety factors greater than the $\eta_{D}$ required for fatigue damage assessment. This confirms, as it was already observed in [11], that an axle design design based only on fatigue assessment could lead to very short inspection periodicities. Alternatively, it can be said that optimisation of the inspection periodicity requires safety factors greater than the minimum values of Fig. 11.

As for the inspection periodicities, we have already suggested that propaga- 
tion lifetime is controlled by the propagation index [9]:

$$
P I=\frac{\Delta K_{\max , o}}{\overline{\Delta K_{t h}}}
$$

where:

$$
\Delta K_{\max , o}=F \cdot \Delta S_{\max } \cdot \sqrt{\pi \cdot \bar{a}_{o}}
$$

is the stress intensity factor calculated at the highest service stresses for the initial crack size $\bar{a}_{o}$. This index has been superimposed onto Fig. 11(b): it can be seen that reasonable inspection periodicities (for the axle of an high speed train) correspond to $0.95<P I<1.15$.

\section{Conclusions}

The current EN standards for fatigue design of a railway axle do not allow to design for a target failure probability. This document describes the approach for the calculation of in service fatigue failure probability of an axle under a given stress spectrum. A series of probabilistic analyses have been carried out on the basis of experimental fatigue properties for EA1N and EA4T obtained within the EURAXLES project and a series of stress spectra from other research projects. The main outcomes of this activity are:

1. there is a minimum safety factor $\eta_{\min }$ for designing with a single load level and the safety factors adopted by EN13103-13104 are close to this value ;

2. we have proposed a safety factor (based on the FKM format) $\eta_{D}$ to be adopted in damage calculations for designing axles with a target reliability under fatigue, provided that "the orgiginal surface condition of the axle material is mantained";

3. the safety factor $\eta_{D}$ to be adopted in damage calculations is higher than the minimum safety factor $\eta_{\min }$ for a single load condition;

4. the safety factor can be further increased if the minimum propagation lifetime, calculated with appropriate crack propagation analyses under the hypothesis of axle surface damaged by impacts, is set to a given mileage; 
5. the relevant design parameter for correlating the maximum service stress to the propagation lifetime is the propagation index $P I=\Delta K_{\max , o} / \overline{\Delta K_{t h}}$.

\section{Acknowledgements}

Part of this research activity (Sec. 1-5) was carried out within WP2 of the EURAXLES project, that was funded by the Seventh Framework (FP7-265706) by the European Commission. D. Regazzi at the time of the research was a PhD student at Politecnico di Milano: after his doctoral degree, he joined LucchiniRS (Lovere, Italy).

\section{References}

[1] EN13103 - Railway Applications - Wheelsets and Bogies - Non Powered Axles Design Method (ISO 2001).

[2] EN13104 - Railway Applications - Wheelsets and Bogies - Powered Axles - Design Method (ISO 2001).

[3] ERRI, Question B136. Wheelset with assembled axle- boxes: design, maintenance and standardisation. Report n. 11 (1979).

[4] S. Cantini, S. Beretta, Structural reliability assessment of railway axles, Lucchini RS, 2011.

[5] U. Zerbst, S. Beretta, G. Köhler, A. Lawton, M. Vormwald, H. T. Beier, C. Klinger, I. Černỳ, J. Rudlin, T. Heckel, et al., Safe life and damage tolerance aspects of railway axles-a review, Engineering Fracture Mechanics 98 (2013) $214-271$.

[6] ERA, Intermediate report on the development of railway safety in the European Union (2013).

[7] ERA, RAILWAY SAFETY PERFORMANCE IN THE EUROPEAN UNION (2014).

[8] R. Lunden, T. Vernersson, A. Ekberg, Railway axle design: to be based on fatigue initiation or crack propagation ?, IMechE, Part F: J. Rail Rapid Transit 224 (2010) 445-453.

[9] L. Mazzola, D. Regazzi, S. Beretta, S. Bruni, Fatigue assessment of old design axles: Service simulation and life extension, IMechE, Part F: J. Rail Rapid Transit.

[10] V. Grubisic, G. Fisher, Procedure for reliable durability validation of train axles, Mat.-Wiss. u. Werkstofftech 32 (12).

[11] S. Beretta, M. Carboni, S. Cervello, Design review of a freight railway axle: fatigue damage versus damage tolerance, Materialwissenschaft und Werkstofftechnik 42 (12) (2011) 1099-1104. 
[12] F. Reuleaux, The Constructor - A Handbook of Machine Design, H.H. Suplee, 1894.

[13] T. M. Nguyen, A. Ourady, X. Lorang, Report on the Fatigue-Equivalent-Load Methodology and the Load Severity Distribution, Tech. Rep. D2.2, EURAXLES Project (2013).

[14] ISO EN1993, Eurocode 3: Design of steel structures, ISO (2005).

[15] E. Haibach, Analytical Strength Assessment of Components in Mechanical Engineering, FKM, Frankfurt, 5th Edition (2003).

[16] W. Schutz, Prediction of fatigue life in the crack initiation and propagation stages - A state of the art survey, Engineering Fracture Mechanics 11 (1979) 405-421.

[17] C. Berger, K.-G. Eulitz, P. Heuler, K.-L. Kotte, H. Naundorf, W. Schuetz, C. Sonsino, A. Wimmer, H. Zenner, Betriebsfestigkeit in germany-an overview, International Journal of Fatigue 24 (6) (2002) 603-625.

[18] E. Haugen, Probabilistic mechanical design, John Wiley \& S., New York, 1980.

[19] W. Nelson, Applied Life Data Analysis, J. Wiley \& Sons, New York, 1981.

[20] P. H. Wirsching, Probabilistic Fatigue Analysis, in: C. Sundararajan (Ed.), Probabilistic Structural Mechanics Handbook, Chapman and Hall, 1995.

[21] J. Thomas, G. Perroud, A. Bignonnet, D. Monnet, Fatigue design and reliability in the automotive industry, in: G. Marquis, J. Solin (Eds.), ESIS 23 - Fatigue Design and Reliability, Elsevier, 1999.

[22] A. Bignonnet, Reliability concepts in fatigue design, in: C. Sonsino, P. McKeighan (Eds.), 2nd Int. Conf. Material and Component Performace under Variable Amplitude Loading, DVM, Darmstad, 2009.

[23] S. Rao, Reliability-Based Design, McGraw-Hill, New York, 1992.

[24] S. Cervello et al., Dataset of Fatigue Properties for European Axle Steels, Int. J. Fatigue sumitted (this special issue).

[25] J. Schijve, Fatigue of Structures and Materials, Kluwer Academic Publishers, Dordrecht, 2001.

[26] S. Beretta, D. Regazzi, Derivation of a common S-N diagram for small scale tests on EA4T specimens and re-analysis of VA data, Tech. Rep. D 3.2.1c, EURAXLES Project (2014).

[27] M. Traupe, H. Meinine, H. Zenner, Sichere und wirtschaftliche Auslegung von Eisenbahnfahrwerken, Tech. Rep. BMBF-Projekt 19 P 0061 A bis F, Clausthal (2004).

[28] S. Lorén, Estimating fatigue limit distributions under inhomogeneous stress conditions, International journal of fatigue 26 (11) (2004) 1197-1205.

[29] C. Eichheimer, M. Luke, Small scale tests, performed by Fraunhofer IWM, Tech. Rep. D 3.2.1b, EURAXLES Project (2014). 
[30] T. M. Nguyen, X. Lorang, Advances in fatigue reliability assessments of railway axles, International Journal of Fatigue submitted, this special issue.

[31] M. Filippini, D. Regazzi, M. Luke, I. Varfolomeev, Fatigue assessment of railway axles: small scale tests and damage calculations, Materialwissenschaft und Werkstofftechnik sumitted.

[32] K. Eulitz, K. Kotte, Damage accumulation-limitations and perspectives for fatigue life assessment, in: Proceedings Material Week, DGM, 2000.

[33] ISO EN1990, Eurocode 0: Basis of structural design, ISO (2002).

[34] JSC, Final report on the results of the Joint Sector Group activities linked to the action plan defined under the Task Force Freight Wagon Maintenance, available at: www.jscrail.eu (2011).

[35] D. Griffin, T728: Impact of corrosion upon the high cycle fatigue properties of GB axle steel- Derivation of safety targets for axle failures, Tech. rep., RSSB (2011).

[36] BS 7910, Guide on methods for assessing the acceptability of flaws in fusion welded structures, British Standards (2005).

[37] A. Watson, K. Timmis, A method of estimating railway axle stress spectra, Engineering Fracture Mechanics 78 (5) (2011) 836-847.

[38] J. Martínez-Casas, L. Mazzola, L. Baeza, S. Bruni, Numerical estimation of stresses in railway axles using a train-track interaction model, International Journal of Fatigue 47 (2013) 18-30.

[39] L. Wei, D7.1 - Procedure to define NDT periodicity as function of vehicle service profile, available at www.widem.org (2005).

[40] V. Grubisic, G. Fisher, Bemessung von Radsatzwellen - Einflussgrssen und Vorgehen bei der Auslegung, Tech. Rep. FB-226, LBF (2005).

[41] S. Bruni, Load spectra for a freight tank wagon estimated by multi-body simulation, unpublished results obtained within SUSTRAIL project (2014).

[42] S. Beretta, M. Carboni, G. Fiore, A. L. Conte, Corrosion-fatigue of A1N railway axle steel exposed to rainwater, Int. J. Fatigue 32 (2010) 952-961.

[43] F. Moretti, S. Beretta, A. L. Conte, D. Straub, Corrosion-fatigue under Rainwater of a Q \& T Steel: Experiments and Probabilistic Description, Procedia Engineering 74 (0) (2014) $12-17$.

[44] A. Haldar, S. Mahadevan, Probability, reliability and statistical methods in engineering design, John Wiley \& S., New York, 2000.

[45] S. Beretta, M. Carboni, Experiments and stochastic model for propagation lifetime of railway axles, Engineering fracture mechanics 73 (17) (2006) 2627-2641.

[46] A. Watson, Implications of Impact Damage on the Structural Integrity of Axles, available at http://esistc24.mecc.polimi.it/BERLIN.html (2010). 
[47] D. Regazzi, S. Beretta, M. Carboni, An investigation about the influence of deep rolling on fatigue crack growth in railway axles made of a medium strength steel, Engineering Fracture Mechanics 131 (2014) 587-601.

[48] J. Rudlin, Overview of the WOLAXIM European Project, available at http://esistc24.mecc.polimi.it/TWI.html (2012). 


\begin{tabular}{|c|c|c|}
\hline & \multicolumn{2}{|c|}{ Consequences of failure } \\
\hline Assessment method & Moderate consequences & Severe consequences \\
\hline Damage tolerance & 1.00 & 1.15 \\
\hline Safe life & 1.15 & 1.35 \\
\hline
\end{tabular}

Table 1: Recommended values for partial safety factor $\gamma_{M f}[14]$. 


\begin{tabular}{c|c|c|} 
& \multicolumn{2}{|c|}{ Consequences of failure } \\
\hline & Moderate consequences & Severe consequences \\
\hline No regular inspection & $j_{D}=1.30$ & $j_{D}=1.50$ \\
\hline Regular inspection & $j_{D}=1.20$ & $j_{D}=1.35$ \\
\hline
\end{tabular}

Table 2: Recommended values for partial safety factor $j_{D}$ according to FKM Guideline [15]. 


\begin{tabular}{|l|l|l|l|}
\hline $\begin{array}{l}N_{D} \\
{[\text { cycles }]}\end{array}$ & $\begin{array}{l}S_{D} \\
{[M P a]}\end{array}$ & $k$ & $\sigma_{\log S}$ \\
\hline $1.2 \cdot 10^{6}$ & 307.3 & 9.2 & 0.026 \\
\hline
\end{tabular}

Table 3: Parameters for the estimated S-N diagram for EA4T

\begin{tabular}{|l|l|l|l|}
\hline $\begin{array}{l}N_{D} \\
{[\text { cycles }]}\end{array}$ & $\begin{array}{l}S_{D} \\
{[M P a]}\end{array}$ & $k$ & $\sigma_{\log S}$ \\
\hline $2.2 \cdot 10^{6}$ & 252.3 & 18.8 & 0.059 \\
\hline
\end{tabular}

Table 4: Parameters for the estimated S-N diagram for EA1N 


\begin{tabular}{|c|c|c|}
\hline & Miner Konzequent & Haibach's method \\
\hline $10^{\mu_{\log D}}=D_{\text {crit }}$ & 0.5287 & 0.6159 \\
\hline$\sigma_{\log D}$ & 0.5836 & 0.5852 \\
\hline
\end{tabular}

Table 5: Statistics for the damage indexes at failure. 


\begin{tabular}{|c|c|}
\hline & $C V_{S_{D}}$ \\
\hline$\sigma_{\log S_{D}}=0.021$ & 0.048 \\
\hline$\sigma_{\log S_{D}}=0.033$ & 0.075 \\
\hline$\sigma_{\log S_{D}}=0.045$ & 0.103 \\
\hline$\sigma_{\log S_{D}}=0.057$ & 0.131 \\
\hline
\end{tabular}

Table 6: Correspondence between scatter of the $\log S_{D}$ and the coefficient of variation of $S_{D}$. 


\begin{tabular}{|l|c|c|}
\hline & \multicolumn{2}{|c|}{ Minimum safety factor $\eta_{\min }$} \\
\hline & $\begin{array}{c}P_{f}=7 \cdot 10^{-5} \\
\hat{\beta}=3.81\end{array}$ & $\begin{array}{c}P_{f}=7 \cdot 10^{-6} \\
\hat{\beta}=4.34\end{array}$ \\
\hline$\sigma_{\log S_{D}}=0.021(\mathrm{CV}=0.048)$ & 1.093 & 1.128 \\
\hline$\sigma_{\log S_{D}}=0.033(\mathrm{CV}=0.075)$ & 1.150 & 1.200 \\
\hline$\sigma_{\log S_{D}}=0.045(\mathrm{CV}=0.103)$ & 1.211 & 1.280 \\
\hline$\sigma_{\log S_{D}}=0.057(\mathrm{CV}=0.131)$ & 1.274 & 1.366 \\
\hline
\end{tabular}

Table 7: Minimum safety factors to be applied for a simple fatigue assessment under a single load $S_{L}$ (deterministic value). 


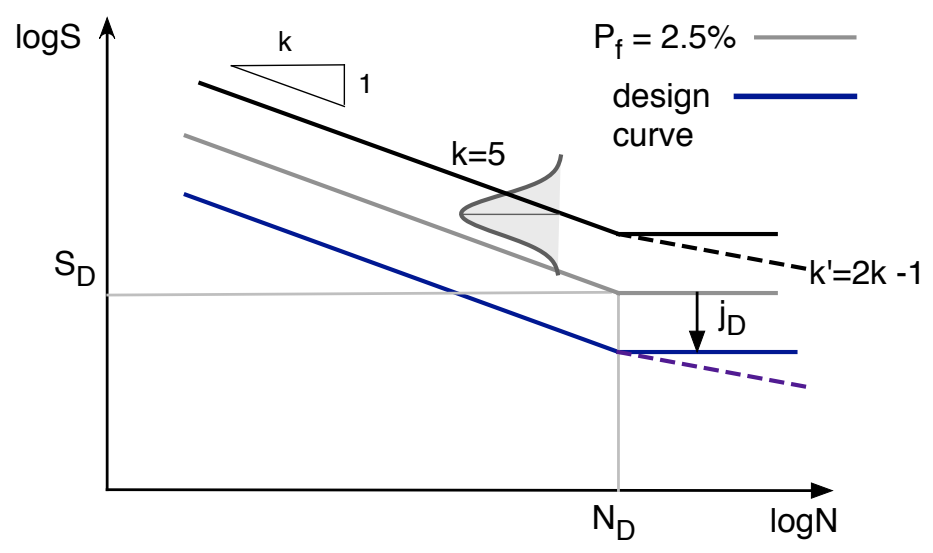

Figure 1: S-N diagram for fatigue assessment by FKM [15]. 


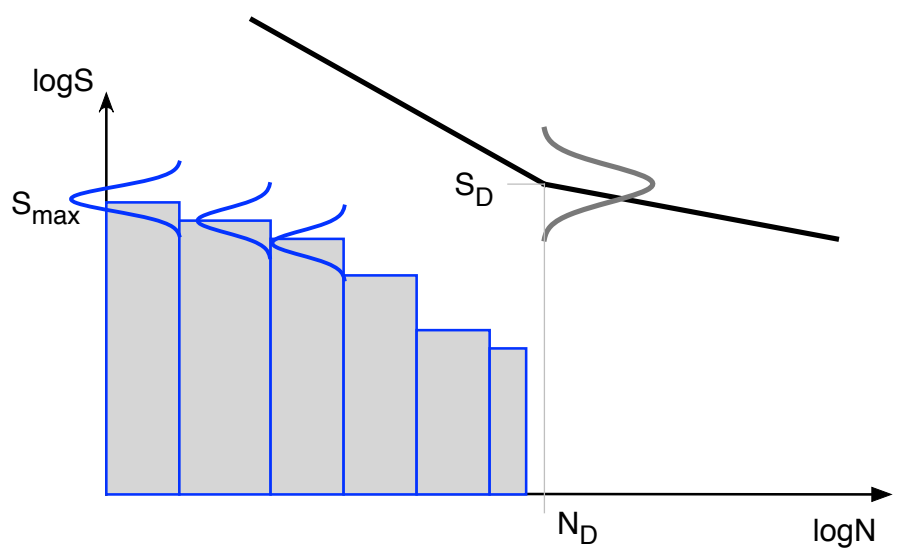

Figure 2: Scheme of the probabilistic damage analysis. 


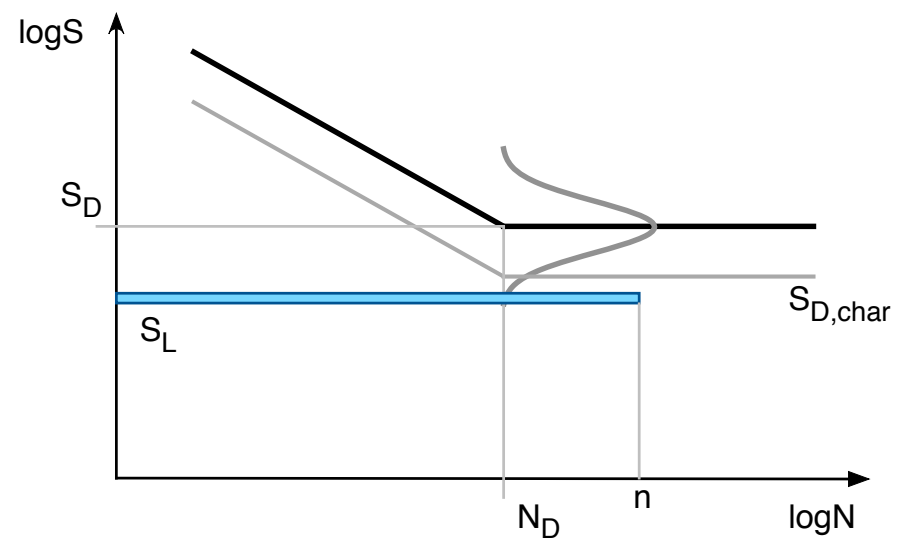

Figure 3: Scheme for a simple probabilistic fatigue assessment under a constant amplitude stress $S_{L}$ 


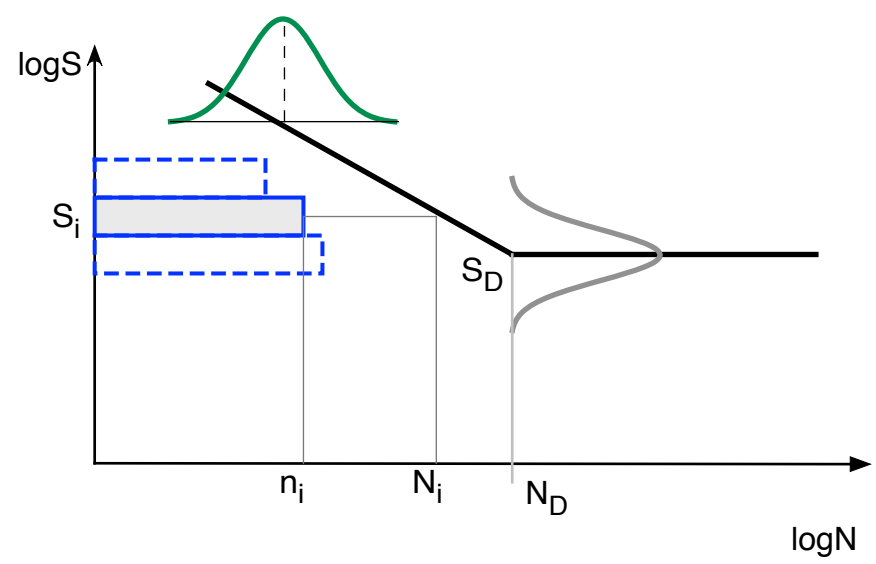

(a)

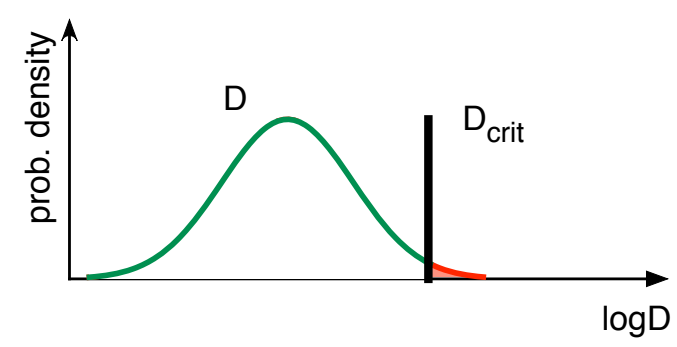

(b)

Figure 4: Probabilistic damage calculation: a) schematic of S-N diagram and damage calculations; b) calculation of failure probability. 


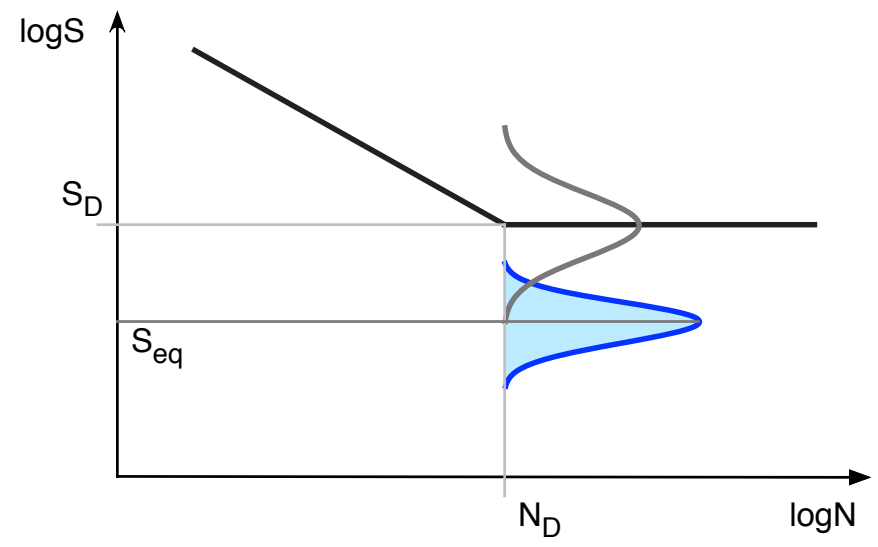

Figure 5: Calculation of failure probability under fatigue damage according to the method adopted by SNCF. 


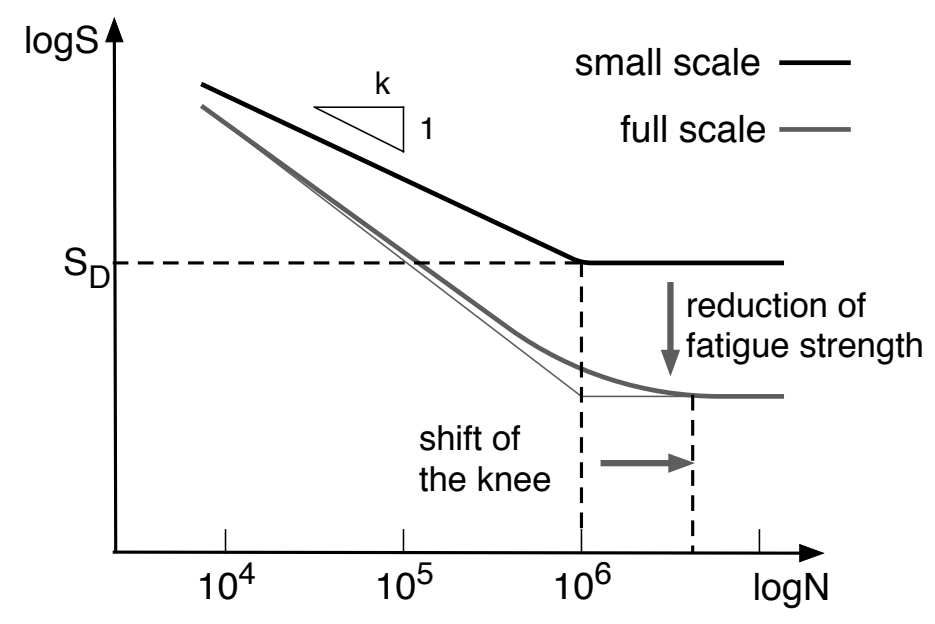

(a)

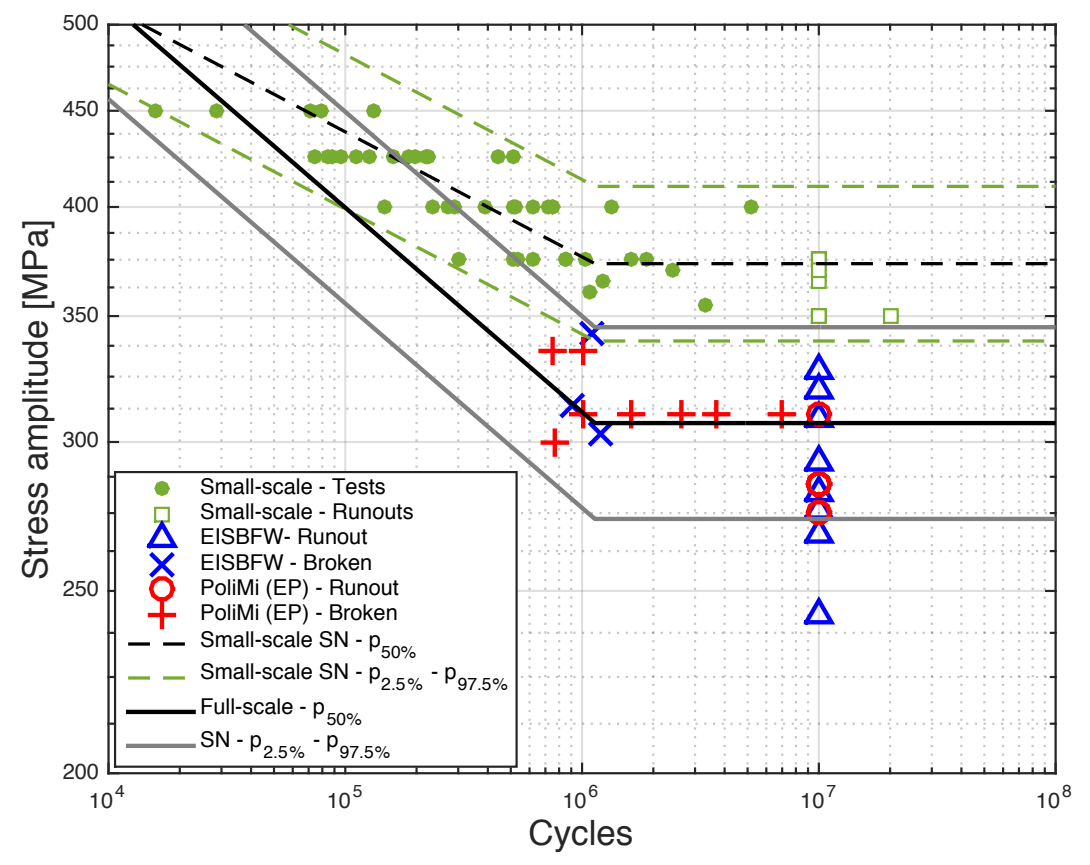

(b)

Figure 6: Prospective S-N diagrama for EA4T: a) schematic by Schijve (adapted from [25]); b) comparison with available data full-scale [27, 24]. 


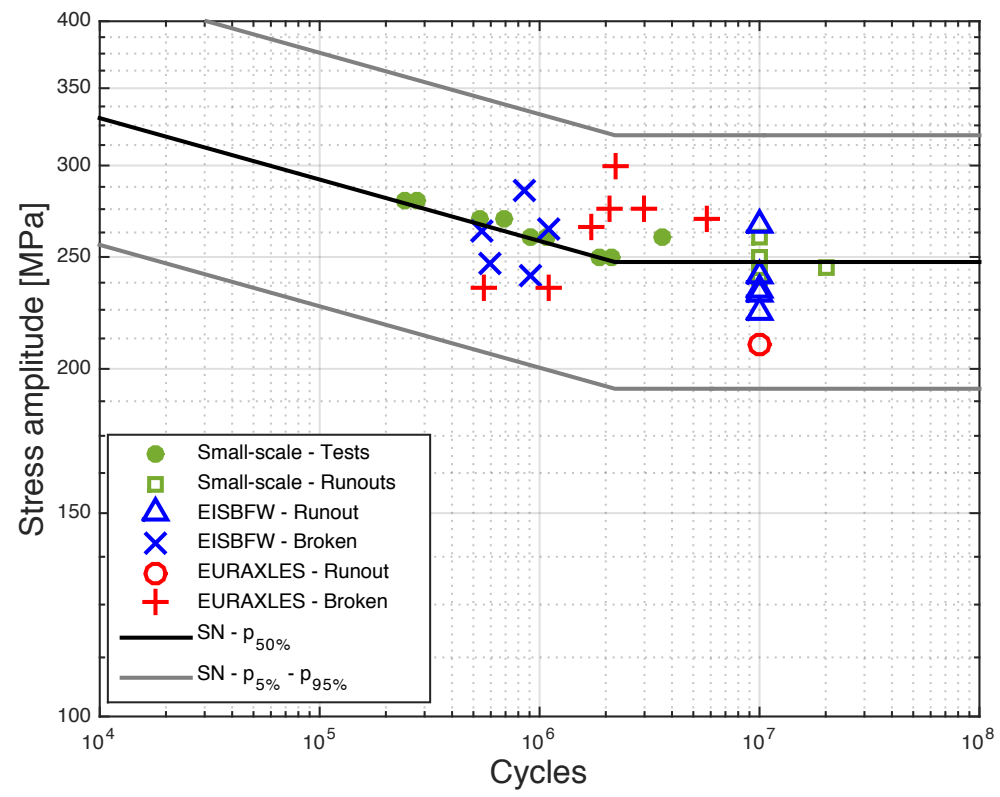

Figure 7: Reference S-N diagram for full-scale axles (in terms of local stress) made of A1N. 


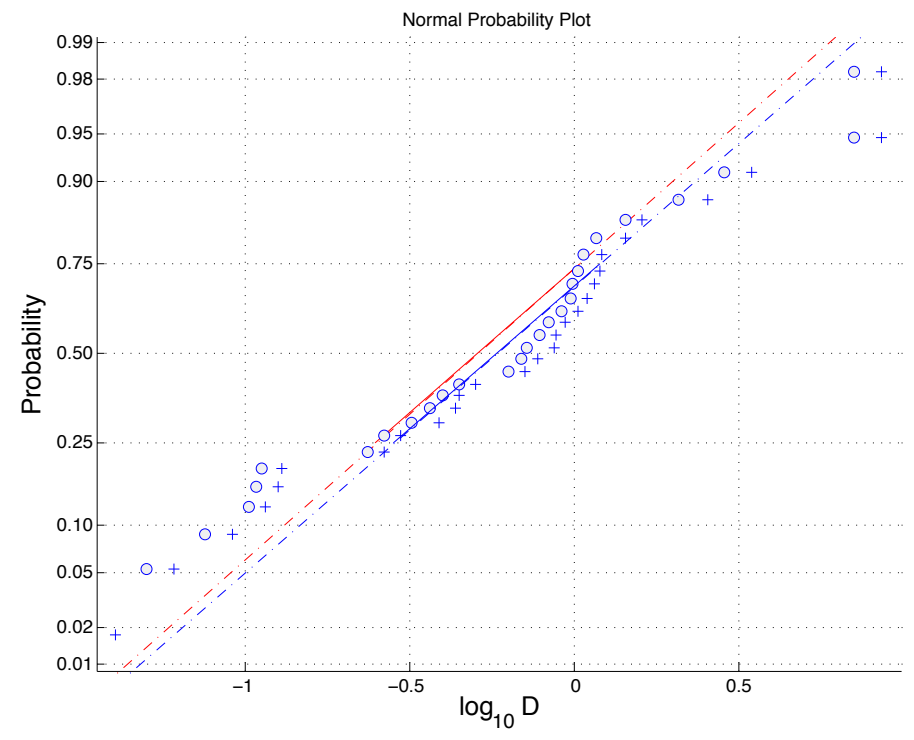

Figure 8: Results about critical Miner Index: a) dependence of $\log D$ on maximum stress in VA tests; b) Normal probability plot for $\log D$. 


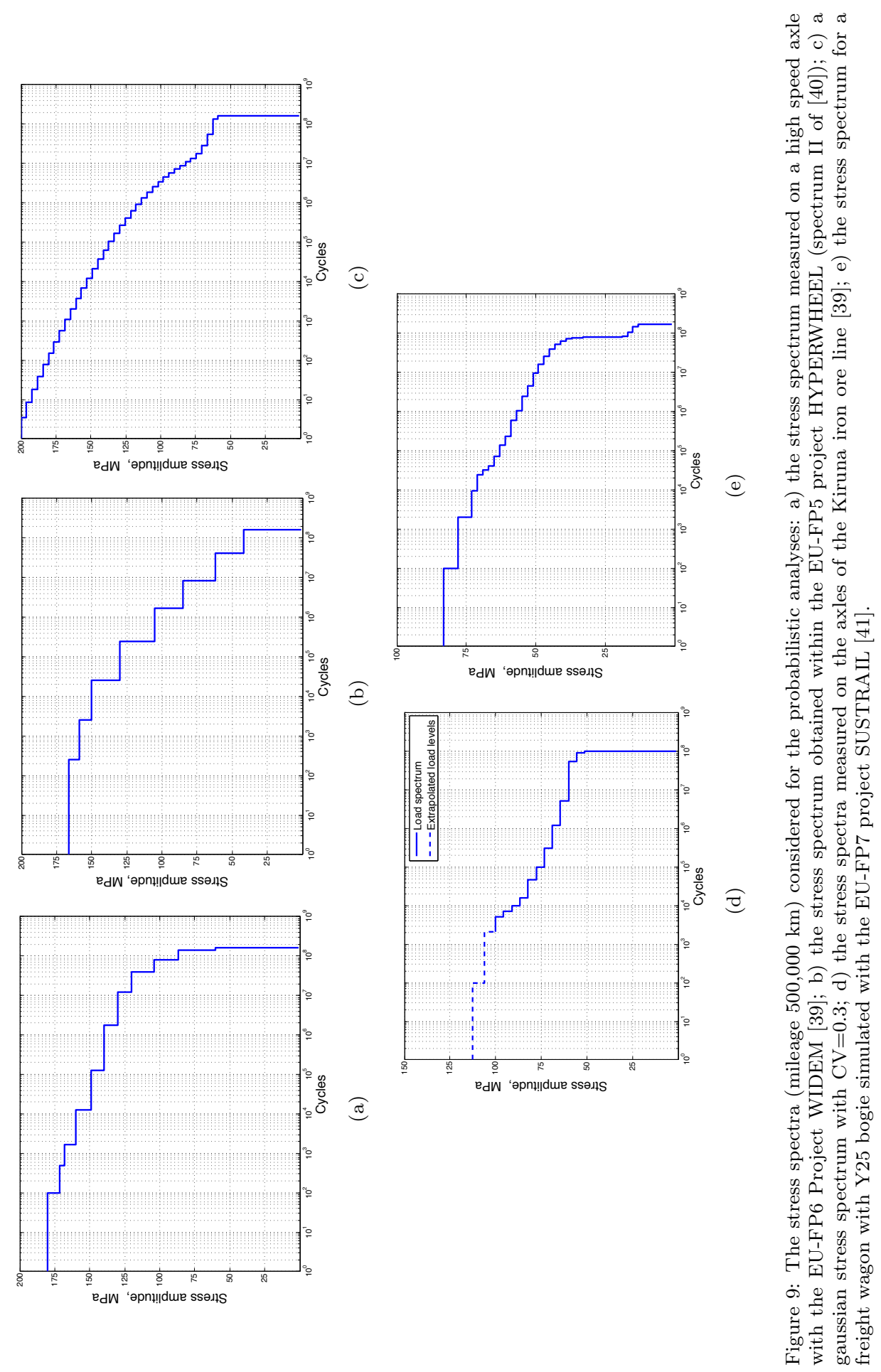




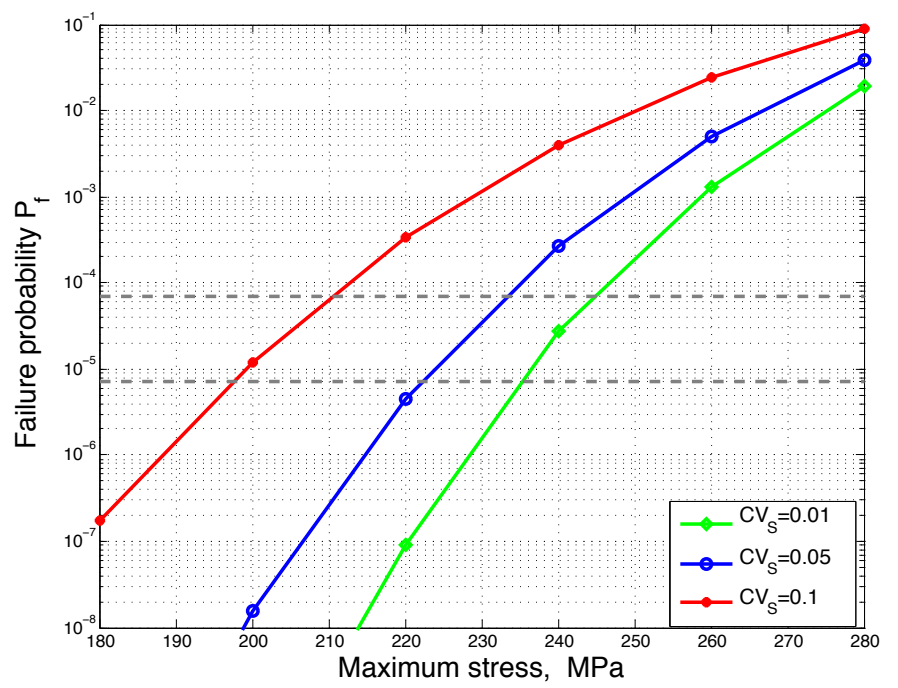

(a)

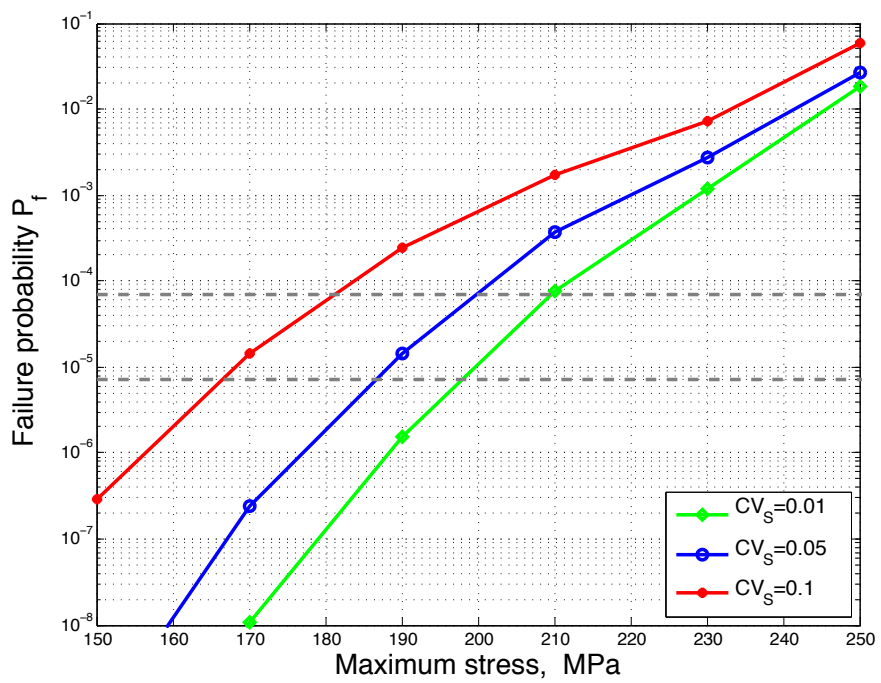

(b)

Figure 10: Dependence of of failure probability on local stress: a) high speed axle under WIDEM stress spectrum (steel EA4T, $\sigma_{\log S_{D}}=0.033$ ); b) freight axle under SUSTrail stress spectrum (steel EA1N, $\left.\sigma_{\log S_{D}}=0.045\right)$. 


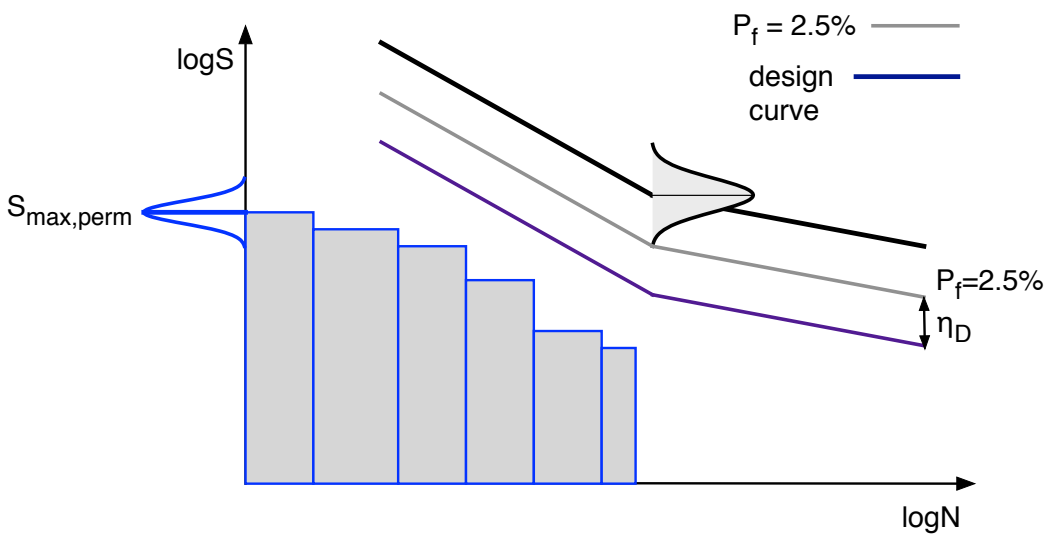

(a)
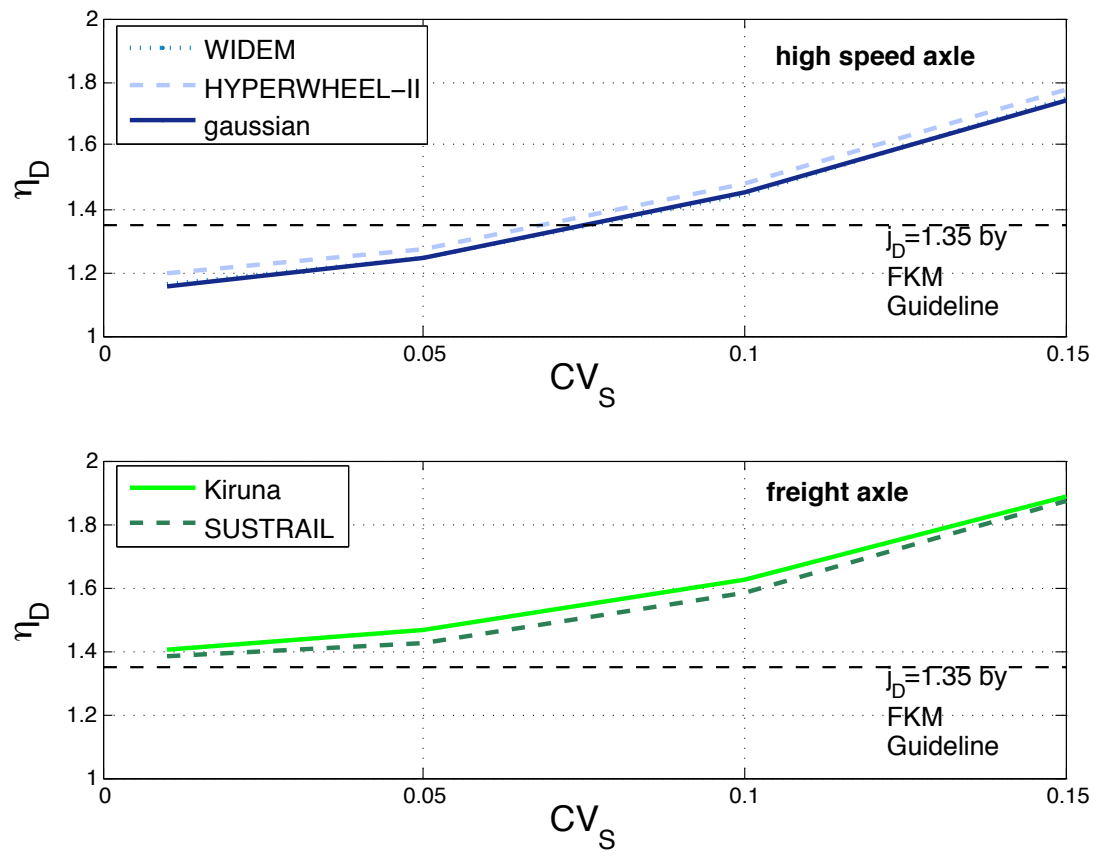

(b)

Figure 11: Definition of a minimum safety factor for fatigue damage calculations with a target reliability $P_{f}=7 \cdot 10^{-6}$ at $10^{7} \mathrm{~km}$ : a) scheme of calculation according to FKM format; b) results for high speed axles (made of EA4T, $\sigma_{\log S_{D}}=0.033$ ) and freight axles (made of $\left.\mathrm{EA} 1 \mathrm{~N}, \sigma_{\log S_{D}}=0.057\right)$. 


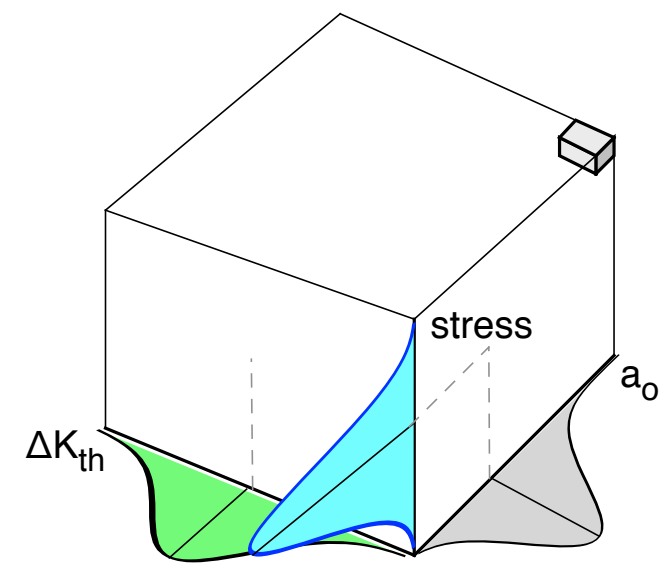

(a)

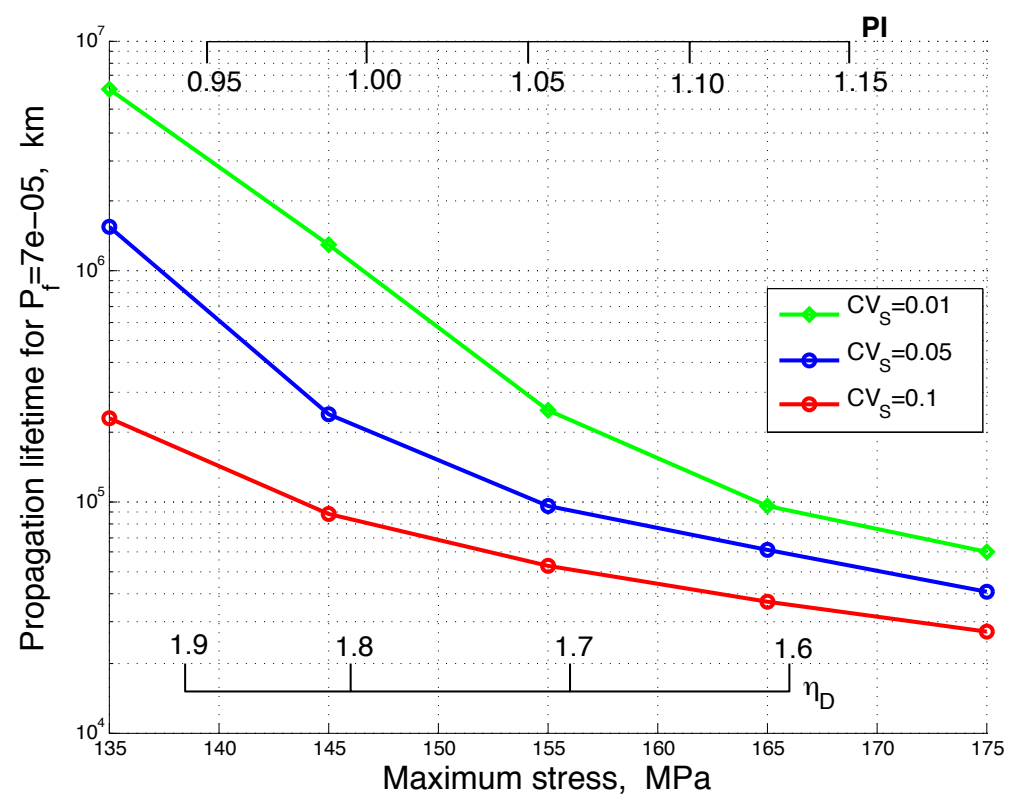

(b)

Figure 12: Calculation of the propagation lifetime corresponding $P_{f}=7 \cdot 10^{-5}$ for an axle made of EA4T subjected to WIDEM stress spectrum and exposed to impacts : a) scheme of calculation according to latin hypersquare approach with a suitable combination of the three variables; b) dependencence of propagation lifetime on $S_{\max }$ for different $C V_{S}$. 
Appendix A. Detailed results for high speed axles made of EA4T steel

\begin{tabular}{|c|c|c|c|c|c|}
\hline \multicolumn{2}{|c|}{} & \multicolumn{2}{|c|}{$\hat{P}_{f, \text { EN1990 }}=7 \cdot 10^{-5}$} & \multicolumn{2}{c|}{$\hat{P}_{f, \text { imp }}=7 \cdot 10^{-6}$} \\
\hline$\sigma_{\text {log } S}$ & $C V_{S}$ & $\begin{array}{c}S_{\text {max,perm }} \\
{[\mathrm{MPa}]}\end{array}$ & $\eta_{D}$ & $\begin{array}{c}S_{\text {max,perm }} \\
{[\mathrm{MPa}]}\end{array}$ & $\eta_{D}$ \\
\hline 0.057 & 0.01 & 227 & 1.242 & 178 & 1.323 \\
0.057 & 0.05 & 218 & 1.273 & 171 & 1.384 \\
0.057 & 0.1 & 199 & 1.404 & 154 & 1.535 \\
0.057 & 0.15 & 174 & 1.606 & 132 & 1.788 \\
\hline 0.045 & 0.01 & 251 & 1.172 & 200 & 1.242 \\
0.045 & 0.05 & 241 & 1.232 & 191 & 1.303 \\
0.045 & 0.1 & 216 & 1.374 & 169 & 1.475 \\
0.045 & 0.15 & 185 & 1.586 & 142 & 1.758 \\
\hline 0.033 & 0.01 & 280 & 1.121 & 226 & 1.162 \\
0.033 & 0.05 & 263 & 1.182 & 212 & 1.242 \\
0.033 & 0.1 & 232 & 1.354 & 182 & 1.444 \\
0.033 & 0.15 & 195 & 1.596 & 151 & 1.747 \\
\hline 0.021 & 0.01 & 311 & 1.061 & 254 & 1.091 \\
0.021 & 0.05 & 287 & 1.152 & 233 & 1.192 \\
0.021 & 0.1 & 245 & 1.354 & 194 & 1.434 \\
0.021 & 0.15 & 204 & 1.616 & 157 & 1.768 \\
\hline
\end{tabular}

Table A.1: Maximum permissible stresses and safety factor to be applied onto the FKM format for the WIDEM stress spectrum (EA4T steel). 


\begin{tabular}{|c|c|c|c|c|c|}
\hline \multicolumn{2}{|c|}{} & \multicolumn{2}{|c|}{$\hat{P}_{f, E N 1990}=7 \cdot 10^{-5}$} & \multicolumn{2}{c|}{$\hat{P}_{f, \text { imp }}=7 \cdot 10^{-6}$} \\
\hline$\sigma_{\log S}$ & $C V_{S}$ & $\begin{array}{c}S_{\text {max,perm }} \\
{[\mathrm{MPa}]}\end{array}$ & $\eta_{D}$ & $\begin{array}{c}S_{\text {max,perm }} \\
{[\mathrm{MPa}]}\end{array}$ & $\eta_{D}$ \\
\hline 0.057 & 0.01 & 190 & 1.255 & 210 & 1.368 \\
0.057 & 0.05 & 185 & 1.311 & 203 & 1.41 \\
0.057 & 0.1 & 168 & 1.438 & 182 & 1.566 \\
0.057 & 0.15 & 147 & 1.651 & 156 & 1.834 \\
\hline 0.045 & 0.01 & 212 & 1.198 & 237 & 1.269 \\
0.045 & 0.05 & 203 & 1.255 & 226 & 1.339 \\
0.045 & 0.1 & 182 & 1.396 & 200 & 1.509 \\
0.045 & 0.15 & 157 & 1.636 & 168 & 1.792 \\
\hline 0.033 & 0.01 & 235 & 1.141 & 267 & 1.198 \\
0.033 & 0.05 & 223 & 1.212 & 251 & 1.269 \\
0.033 & 0.1 & 195 & 1.368 & 216 & 1.481 \\
0.033 & 0.15 & 165 & 1.636 & 179 & 1.778 \\
\hline 0.021 & 0.01 & 261 & 1.085 & 302 & 1.113 \\
0.021 & 0.05 & 241 & 1.17 & 276 & 1.226 \\
0.021 & 0.1 & 206 & 1.382 & 230 & 1.467 \\
0.021 & 0.15 & 172 & 1.651 & 187 & 1.806 \\
\hline
\end{tabular}

Table A.2: Maximum permissible stresses and safety factor to be applied onto the FKM format for the HYPERWHEEL-2 stress spectrum (EA4T steel). 


\begin{tabular}{|c|c|c|c|c|c|}
\hline \multicolumn{2}{|c|}{} & \multicolumn{2}{|c|}{$\hat{P}_{f, E N 1990}=7 \cdot 10^{-5}$} & \multicolumn{2}{c|}{$\hat{P}_{f, \text { imp }}=7 \cdot 10^{-6}$} \\
\hline$\sigma_{\log S}$ & $C V_{S}$ & $\begin{array}{c}S_{\text {max,perm }} \\
{[\mathrm{MPa}]}\end{array}$ & $\eta_{D}$ & $\begin{array}{c}S_{\text {max,perm }} \\
{[\mathrm{MPa}]}\end{array}$ & $\eta_{D}$ \\
\hline 0.057 & 0.01 & 258 & 1.242 & 241 & 1.323 \\
0.057 & 0.05 & 251 & 1.283 & 232 & 1.384 \\
0.057 & 0.1 & 228 & 1.404 & 208 & 1.545 \\
0.057 & 0.15 & 200 & 1.606 & 179 & 1.788 \\
\hline 0.045 & 0.01 & 288 & 1.182 & 272 & 1.242 \\
0.045 & 0.05 & 276 & 1.222 & 259 & 1.303 \\
0.045 & 0.1 & 247 & 1.364 & 229 & 1.485 \\
0.045 & 0.15 & 212 & 1.606 & 192 & 1.768 \\
\hline 0.033 & 0.01 & 319 & 1.121 & 306 & 1.162 \\
0.033 & 0.05 & 302 & 1.182 & 288 & 1.242 \\
0.033 & 0.1 & 265 & 1.343 & 248 & 1.444 \\
0.033 & 0.15 & 225 & 1.586 & 204 & 1.747 \\
\hline 0.021 & 0.01 & 354 & 1.061 & 344 & 1.101 \\
0.021 & 0.05 & 328 & 1.162 & 316 & 1.202 \\
0.021 & 0.1 & 280 & 1.343 & 263 & 1.444 \\
0.021 & 0.15 & 233 & 1.626 & 213 & 1.768 \\
\hline
\end{tabular}

Table A.3: Maximum permissible stresses and safety factor to be applied onto the FKM format for a gaussian stress spectrum (EA4T steel). 
Appendix B. Detailed results for freight axles made of EA1N steel

\begin{tabular}{|c|c|c|c|c|c|}
\hline \multicolumn{2}{|c|}{} & \multicolumn{2}{|c|}{$\hat{P}_{f, \text { EN1990 }}=7 \cdot 10^{-5}$} & \multicolumn{2}{c|}{$\hat{P}_{f, \text { imp }}=7 \cdot 10^{-6}$} \\
\hline$\sigma_{\text {logS }}$ & $C V_{S}$ & $\begin{array}{c}S_{\text {max,perm }} \\
{[\mathrm{MPa}]}\end{array}$ & $\eta_{D}$ & $\begin{array}{c}S_{\text {max,perm }} \\
{[\mathrm{MPa}]}\end{array}$ & $\eta_{D}$ \\
\hline 0.057 & 0.01 & 170 & 1.303 & 158 & 1.404 \\
0.057 & 0.05 & 164 & 1.364 & 152 & 1.465 \\
0.057 & 0.1 & 150 & 1.4845 & 137 & 1.626 \\
0.057 & 0.15 & 130 & 1.727 & 118 & 1.889 \\
\hline 0.045 & 0.01 & 189 & 1.242 & 178 & 1.323 \\
0.045 & 0.05 & 181 & 1.303 & 170 & 1.384 \\
0.045 & 0.1 & 162 & 1.465 & 150 & 1.566 \\
0.045 & 0.15 & 140 & 1.687 & 126 & 1.869 \\
\hline 0.033 & 0.01 & 209 & 1.182 & 201 & 1.242 \\
0.033 & 0.05 & 198 & 1.263 & 189 & 1.323 \\
0.033 & 0.1 & 174 & 1.424 & 162 & 1.525 \\
0.033 & 0.15 & 147 & 1.687 & 134 & 1.848 \\
\hline 0.021 & 0.01 & 232 & 1.141 & 226 & 1.162 \\
0.021 & 0.05 & 215 & 1.222 & 207 & 1.263 \\
0.021 & 0.1 & 184 & 1.424 & 173 & 1.525 \\
0.021 & 0.15 & 153 & 1.707 & 140 & 1.869 \\
\hline
\end{tabular}

Table B.1: Maximum permissible stresses and safety factor to be applied onto the FKM format for the Kiruna stress spectrum (EA1N steel). 


\begin{tabular}{|c|c|c|c|c|c|}
\hline \multicolumn{2}{|c|}{} & \multicolumn{2}{|c|}{$\hat{P}_{f, E N 1990}=7 \cdot 10^{-5}$} & \multicolumn{2}{c|}{$\hat{P}_{f, \text { imp }}=7 \cdot 10^{-6}$} \\
\hline$\sigma_{\log S}$ & $C V_{S}$ & $\begin{array}{c}S_{\text {max,perm }} \\
{[\mathrm{MPa}]}\end{array}$ & $\eta_{D}$ & $\begin{array}{c}S_{\text {max,perm }} \\
{[\mathrm{MPa}]}\end{array}$ & $\eta_{D}$ \\
\hline 0.057 & 0.01 & 186 & 1.283 & 173 & 1.384 \\
0.057 & 0.05 & 180 & 1.323 & 167 & 1.424 \\
0.057 & 0.1 & 164 & 1.444 & 150 & 1.586 \\
0.057 & 0.15 & 143 & 1.667 & 128 & 1.869 \\
\hline 0.045 & 0.01 & 206 & 1.222 & 195 & 1.283 \\
0.045 & 0.05 & 198 & 1.263 & 186 & 1.343 \\
0.045 & 0.1 & 177 & 1.424 & 164 & 1.525 \\
0.045 & 0.15 & 152 & 1.646 & 138 & 1.828 \\
\hline 0.033 & 0.01 & 230 & 1.162 & 220 & 1.202 \\
0.033 & 0.05 & 217 & 1.222 & 206 & 1.283 \\
0.033 & 0.1 & 190 & 1.404 & 177 & 1.505 \\
0.033 & 0.15 & 160 & 1.667 & 147 & 1.808 \\
\hline 0.021 & 0.01 & 258 & 1.081 & 250 & 1.121 \\
0.021 & 0.05 & 236 & 1.182 & 227 & 1.222 \\
0.021 & 0.1 & 201 & 1.384 & 189 & 1.485 \\
0.021 & 0.15 & 167 & 1.667 & 153 & 1.828 \\
\hline
\end{tabular}

Table B.2: Maximum permissible stresses and safety factor to be applied onto the FKM format for the SUSTRAIL stress spectrum (EA1N steel). 